Check for updates

Cite this: RSC Adv., 2019, 9, 6515

Received 25th September 2018 Accepted 11th January 2019

DOI: $10.1039 / c 8 r a 07943 a$

rsc.li/rsc-advances

\section{Synthesis, characterization and activity performance of nickel-loaded spent FCC catalyst for pine gum hydrogenation}

\author{
Xiaopeng Chen, ${ }^{\text {a }}$ Lu Ren, ${ }^{a}$ Muhammad Yaseen, ${ }^{\text {ab }}$ Linlin Wang, (D) a Jiezhen Liang, ${ }^{a}$ \\ Ruixue Liang, ${ }^{a}$ Xiankun $\mathrm{Chen}^{\mathrm{a}}$ and Huiqing Guo ${ }^{\mathrm{a}}$
}

\begin{abstract}
A Ni-based catalyst supported over a spent fluid catalytic cracking (FCC) catalyst was prepared by a wet impregnation method. The catalytic characteristic was investigated in pine gum hydrogenation. Optimum conditions for catalyst preparation were obtained as: $15 \% \mathrm{Ni}$ loading, $723 \mathrm{~K}$ calcination temperature, and $723 \mathrm{~K}$ reduction temperature for $2.5 \mathrm{~h}$. The characterization results indicate that the specific surface area of the spent catalyst increased from $65.70 \mathrm{~m}^{2} \mathrm{~g}^{-1}$ to $67.78 \mathrm{~m}^{2} \mathrm{~g}^{-1}$ after calcination. The $\mathrm{H}_{2}$-TPR profile of the spent FCC catalyst exhibited two reduction peaks at $1123{ }^{\circ} \mathrm{C}$ and $670{ }^{\circ} \mathrm{C}$. The TG curves showed that the second and third steps occur at $440 \mathrm{~K}$ and $550 \mathrm{~K}$, respectively, having a total weight loss of $16 \%$. The $\mathrm{NiO}$ grains possess rhombus particles on the surface or between the layers of the supported $\mathrm{NiO}$ catalyst. After activation in $\mathrm{H}_{2}$ flow, the metallic $\mathrm{Ni}$ loads on the support with no covalent bond between them. The $\mathrm{NH}_{3}$-TPD results indicated that the spent FCC catalyst held an obvious distribution of weakly acidic sites, and the acid sites became stronger after loading the catalyst with $\mathrm{Ni}$. The hydrogenation products of pine gum were identified by GC-MS and a reaction mechanism was proposed. This study demonstrated its cost-effectiveness, environment-friendly nature and that the utilization of a spent FCC catalyst can be effectively applied as an alternative approach to pine gum hydrogenation on an industrial level.
\end{abstract}

\section{Introduction}

Pine gum is one of the biggest biomass oil resources in the world. Because of the suitable climate, pine gum has spread all over China, particularly in the Sichuan, Yunnan, Guizhou, Guangxi, Fujian, Anhui and Jiangxi provinces. ${ }^{1}$ Rosin and turpentine oil can be obtained from pine gum by distillation. The main component of rosin is abietic acid that contains a conjugated double bond, which upon oxidation deepens its color and brittleness, increases the hydroxyl contents and ultimately enhances its polarity. Thus, it causes the reduction in its solubility in gasoline or petroleum ether and decreases its use in plastics and ink industry.

Hydrogenated rosin is used in many industries, ${ }^{2}$ such as adhesives ${ }^{3-10}$ coatings, ${ }^{11}$ printing ink,${ }^{12}$ corrosion prevention, ${ }^{13}$ chewing gum ${ }^{\mathbf{1 4}, 15}$ and medicine, ${ }^{\mathbf{1 6}}$ due to its good oxidation resistance, light color, low brittleness and high thermal stability.

${ }^{a}$ Guangxi Key Laboratory of Petrochemical Resources Processing and Process Intensification Technology, School of Chemistry and Chemical Engineering, Guangxi University, Nanning 53004, PR China. E-mail: lilm@gxu.edu.cn; Fax: +86-771-3233718; Tel: +86-771-3272702

${ }^{b}$ Institute of Chemical Sciences, University of Peshawar, Peshawar, 25120, KP, Pakistan
In general, hydrogenated rosin is produced by melting rosin between $220-270{ }^{\circ} \mathrm{C}$ in a pressure range of $10-25 \mathrm{MPa}$ using noble metal $(\mathrm{Pd} / \mathrm{C})$ as the catalyst. ${ }^{17,18}$ Some major drawbacks of this process are the rigorous conditions, high catalyst costs, and a large-scale equipment investment. Similarly, the high temperature operation inevitably results in a series of side reactions of dehydrogenation and decarboxylation, which can decrease the performance of rosin products. The other method of producing hydrogenated rosin is the solution method of mixing rosin and no. 200 industrial grade solvent oil together. ${ }^{19}$ This method improves the condition of the reaction in a temperatures range of $120-150{ }^{\circ} \mathrm{C}$ and mild pressures of 4$5 \mathrm{MPa}^{20}$ This method was developed as pine gum hydrogenation and finally the no. 200 industrial grade solvent oil was replaced by turpentine oil. Because turpentine oil originally comes from pine gum, its mass transfer gets promoted, which results in the color and luster of the product.

A Pd/C catalyst has been ubiquitously used for the catalytic hydrogenation of rosin..$^{21,22} \mathrm{~A}$ major question of this process is the uncontrolled process cost due to Pd utilization. Thus, developing a base metal catalyst, which is cost-effective, without sacrificing the activity is becoming more critical.

Fluid catalytic cracking (FCC) is a central technology in the secondary manufacturing of crude oil ${ }^{23}$ and the amount of catalyst used in this process is more than $90 \mathrm{kt} \mathrm{a}^{-1} \cdot{ }^{24}$ Owing to 

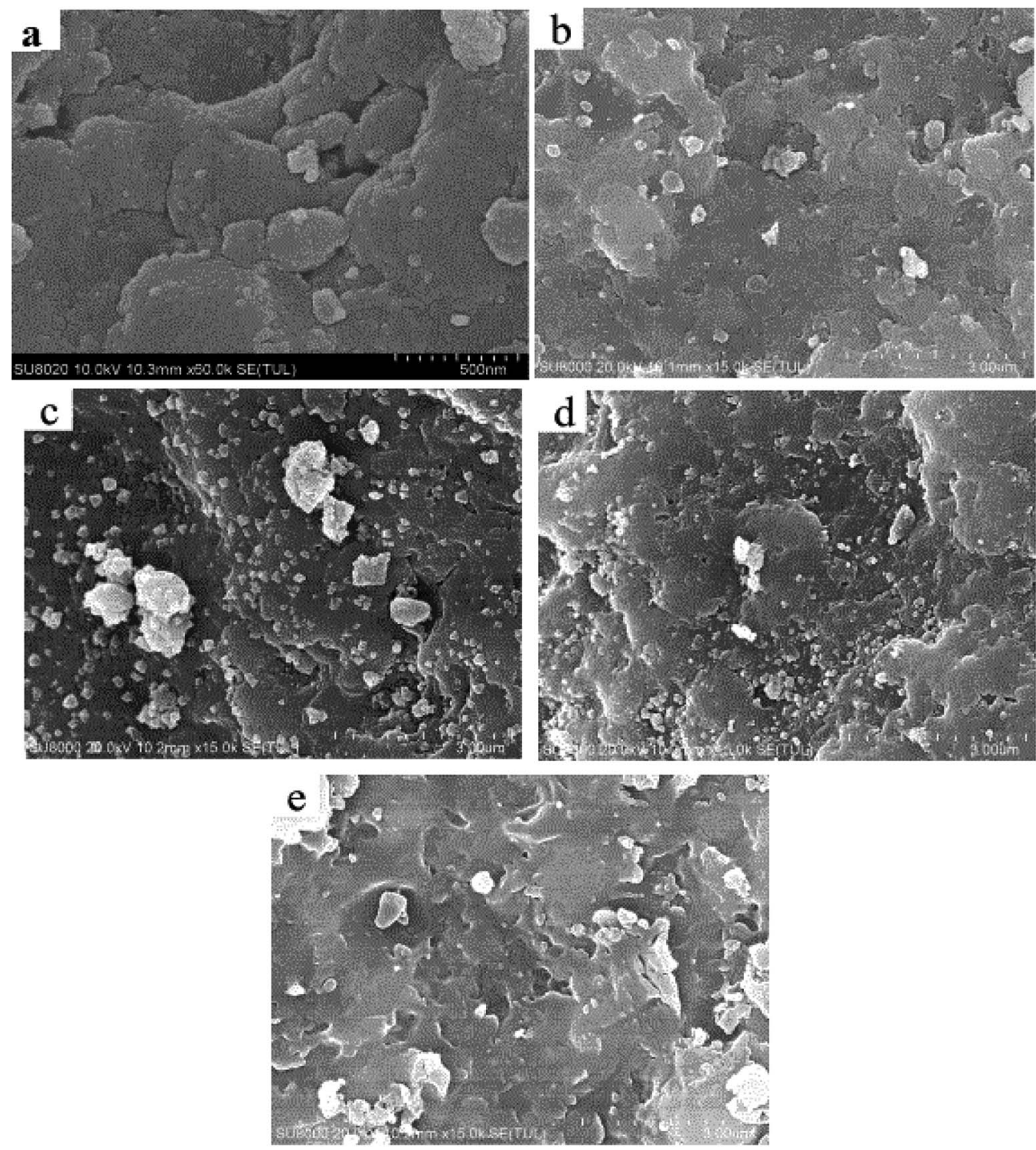

Fig. 1 SEM images of (a) spent FCC catalyst, (b) calcined spent FCC catalyst, (c) supported NiO catalyst, (d) supported nickel catalyst and (e) used Ni loaded catalyst.

Table 1 Textural Characterization of various catalysts using BET method

\begin{tabular}{llll}
\hline FCC catalyst sample & $\begin{array}{l}\text { BET surface } \\
\text { area }\left(\mathrm{m}^{2} \mathrm{~g}^{-1}\right)\end{array}$ & $\begin{array}{l}\text { Pore volume } \\
\left(\mathrm{cm}^{3} \mathrm{~g}^{-1}\right)\end{array}$ & $\begin{array}{l}\text { Pore size } \\
(\mathrm{nm})\end{array}$ \\
\hline New & 170.8 & 0.076 & 3.097 \\
Spent & 65.70 & 0.112 & 7.091 \\
Calcined spent & 67.78 & 0.123 & 7.453 \\
Supported Ni & 56.84 & 0.095 & 7.078
\end{tabular}

carbonaceous deposits formed over FCC catalysts during operation, the acid sites of catalysts are reduced and the mass transfer in the channels of zeolites is hampered, which can considerably decrease catalytic activity. ${ }^{25}$ The analysis of the state of coke deposits on spent FCC catalysts shows that there are two different types of coke i.e. soluble and insoluble..$^{25,26}$ The former includes aromatics with 2-3 rings adsorbed on the external surface and PAHs with 2-7 rings adsorbed inside the pore, while the latter is confirmed as an amorphous structure, and may consist of a disordered arrangement of polyaromatic molecules. Bibby et $a .^{27}$ and Behera et al. ${ }^{28}$ presented the formation, nature and properties of coke, and studied the techniques for analyzing and characterizing coke. The FCC catalysts literally go to waste as they are poisoned by the adsorption of heavy metal ions such as V, Ni and Sn in the rework process. According to the reported literature, almost $100 \%$ of the metal contaminants in feed is decomposed and deposited on the FCC catalyst surface causing its deactivation. ${ }^{29,30}$ Discarding these spent catalysts has not only led to an economic loss but also resulted in the air, underground water and solids pollution.

In order to address these issues, many studies have focused on making full use of the spent FCC catalyst. Wang et al. ${ }^{31}$ investigated the conversion of pinenes to pinane over nickel supported over a spent FCC catalyst, with a total pinenes 


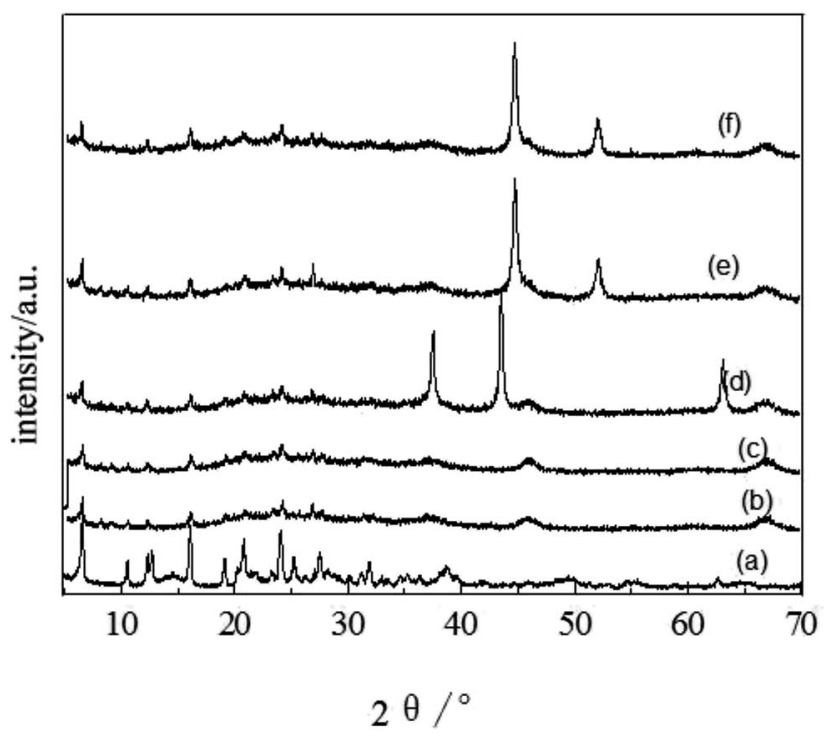

Fig. 2 XRD patterns of (a) fresh FCC catalyst, (b) spent FCC catalyst, (c) calcined spent FCC catalyst, (d) supported $\mathrm{NiO}$ catalyst, (e) supported $\mathrm{Ni}$ catalyst and (f) used Ni loaded catalyst.

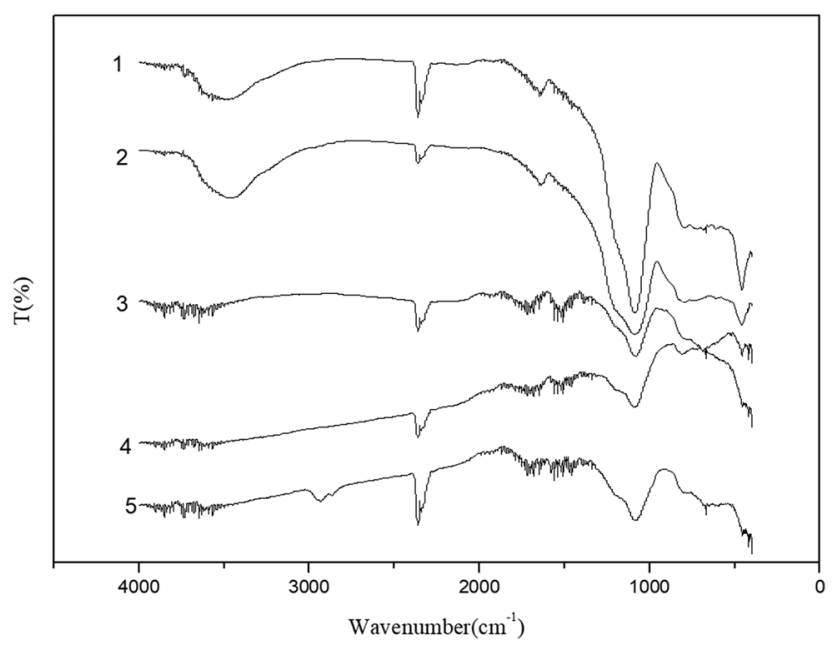

Fig. 3 IR spectra of (1) spent FCC catalyst, (2) calcined spent FCC catalyst, (3) supported $\mathrm{NiO}$ catalyst, (4) supported Ni catalyst and (5) used Ni loaded catalyst.

conversion of $98.48 \%$ and a cis-trans ratio of $13.89 . \mathrm{Lu}^{32}$ introduced a novel method of using spent FCC catalysts or additives to upgrade $n$-butene into more useful propylene, iso-butene, iso-butane and even gasoline. Commingled polymer waste and polyolefin waste were converted into chemicals and valuable hydrocarbons, respectively, over spent FCC commercial catalysts. ${ }^{33,34}$ Some studies evaluated "used" FCC catalysts for the recycling of polymer wastes, ${ }^{35,36}$ while removal of metallic ions using spent FCC catalysts have also been reported. ${ }^{37,38}$ To the best of our knowledge, no work has been reported on the reuse of these poisonous ions, such as, $\mathrm{Ni}, \mathrm{V}$ and Fe supported over FCC spent catalysts for the hydrogenation of pine gum.

In this study, we report on metal ions ( $\mathrm{Ni}, \mathrm{Fe}$, and $\mathrm{V}$ ) deposited on the surface of a spent FCC catalyst in the hydrogenation reaction of pine gum. This work makes full use of the poisoning $\mathrm{Ni}$ ions and the molecular sieve structure of spent FCC catalysts to prepare load-type non-noble metal catalysts by a wet impregnation method followed by hydrogen reduction and applied in the catalytic hydrogenation of pine gum, demonstrating high activity and selectivity. The hydrogenation rosin product exhibits high quality properties $(1.9 \mathrm{wt} \%$ abietic acid, acid value $164.2 \mathrm{mg} \mathrm{g}^{-1}$, and Lovibond color number, red 0.7 , yellow 4.0). The as-prepared catalysts were characterized using scanning electron microscopy (SEM), Brunauer-Emmett-Teller (BET), X-ray diffraction (XRD), Fourier transform infra-red spectroscopy (FT-IR), hydrogen programmed temperature reduction $\left(\mathrm{H}_{2}-\mathrm{TPR}\right)$, nitrogen programmed temperature desorption $\left(\mathrm{N}_{2}\right.$-TPD), and thermogravimetric differential thermal analysis (TG-DTA). The reaction products were analyzed using gas chromatography mass spectrometry (GC-MS) based on which a proper reaction mechanism was proposed. This study provides a new and environment-friendly route for the regeneration and application of spent FCC catalysts with a highly cost-effective nature and enhanced catalytic activity and selectivity for pine gum hydrogenation on an industrial level.

\section{Materials and methods}

\subsection{Materials}

The spent FCC catalyst was purchased from Guangxi Tiandong Oil Refinery. $\mathrm{Ni}\left(\mathrm{NO}_{3}\right)_{2} \cdot 6 \mathrm{H}_{2} \mathrm{O}$ (over $98 \mathrm{wt} \%$ ) was purchased from Chengdu Kelong Chemical Co. China. Pine gum was purchased from Guangxi Wuzhou Pine Chemical Co., Ltd., China. The pine gum contains palustric acid (54.5 wt\%), dehydroabietic acid (4.4 wt\%), abietic acid (10.4 wt\%) and neoabietic acid (15.0 wt\%).

\subsection{Catalyst preparation}

The catalysts were prepared for support by a wet impregnation method reported previously. ${ }^{39,40}$ The calcined spent FCC catalyst was impregnated with a desired amount of $\mathrm{Ni}\left(\mathrm{NO}_{3}\right)_{2} \cdot 6 \mathrm{H}_{2} \mathrm{O}$ solution. After being dried at $120{ }^{\circ} \mathrm{C}$, the precursors were maintained at 523-923 K for $3 \mathrm{~h}$ to control the decomposition of nitrate. Then, the precursors were reduced for $2.5 \mathrm{~h}$ at 523-923 $\mathrm{K}$ under a hydrogen flow in an automatic-temperaturecontrolled tube furnace reactor, which was connected with $\mathrm{N}_{2}$ and $\mathrm{H}_{2}$ piping.

\subsection{Catalyst characterization}

The morphology of the catalyst was analyzed in a JEOL JM-6400 SU8020 scanning electronic microscope (SEM), using an acceleration voltage of $7 \mathrm{kV}$. FTIR spectra of the samples were recorded using a spectrophotometer (NICOLET 6700, wavelength $400-4000 \mathrm{~cm}^{-1}$ ) at room temperature. Powder X-ray diffraction (XRD) was performed in a Rigaku analytical diffractometer model D/MAX-UItima IV with a $\mathrm{Cu}-\mathrm{K}$ anode, at $40 \mathrm{kV}$ and $200 \mathrm{~mA}$, while scanning the sample over a Bragg angle $(2 \mathrm{~h})$ of $5^{\circ}$ to $70^{\circ}$. The specific surface area (BET), total pore volume and average pore diameter were measured by $\mathrm{N}_{2}$ adsorption at 

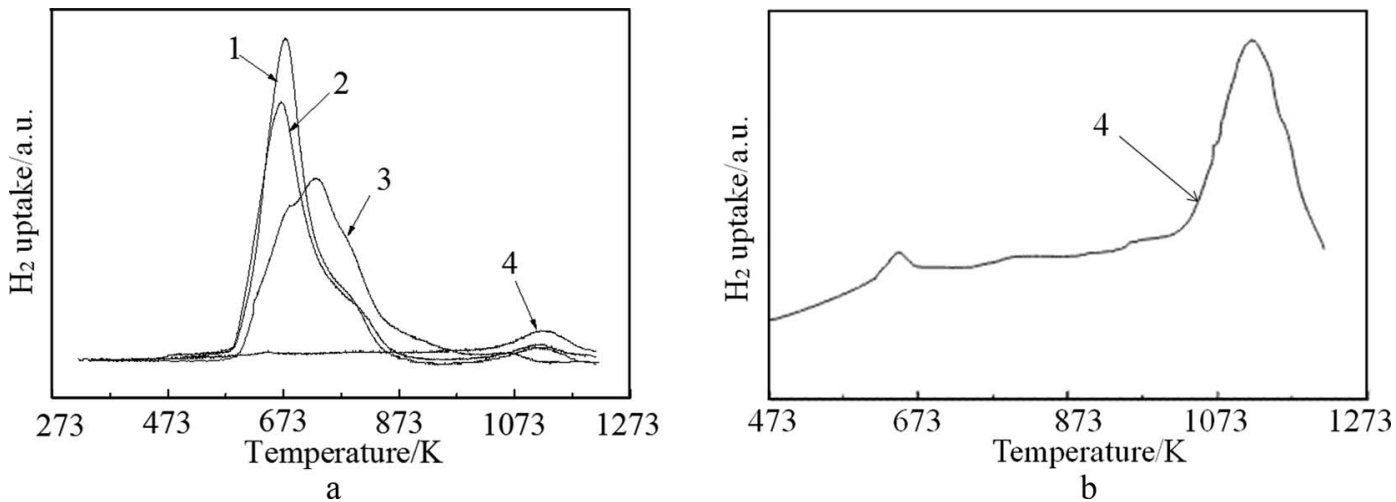

b

Fig. 4 TPR profiles of (1) NiO/spent FCC catalyst, (2) NiO/calcined spent FCC catalyst; (3) NiO/fresh FCC catalyst; (4) spent FCC catalyst.

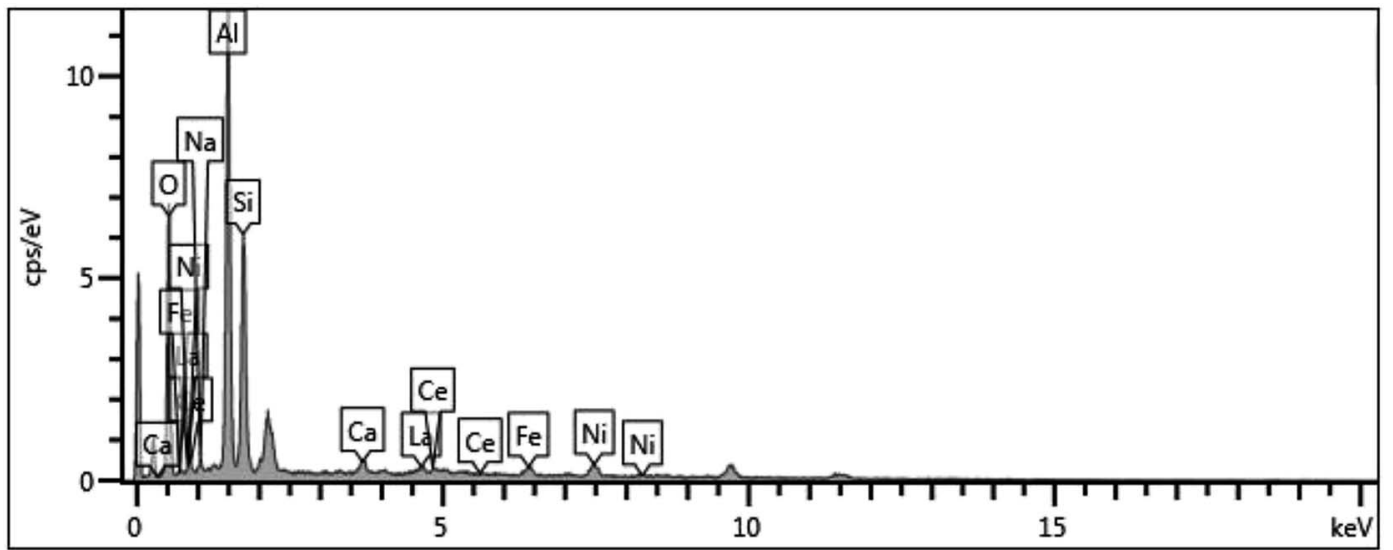

Fig. 5 Elemental Composition of spent FCC catalyst from EDS.

$77 \mathrm{~K}$ in a Builder SSA-4300 Surface Area and Pore Size Analyzer (with outgassing of the samples at $523 \mathrm{~K}$ during $2.5 \mathrm{~h}$ ). Thermal stabilities of the samples were obtained by using a thermogravimetric analyzer (NETZSCH STA 409 PC/PG TG-DT) at a scanning rate of $10{ }^{\circ} \mathrm{C} \mathrm{min}^{-1}$ in a temperature range of $25-1073{ }^{\circ} \mathrm{C}$ in $\mathrm{N}_{2}$ atmosphere. Hydrogen temperature-programmed reduction $\left(\mathrm{H}_{2}\right.$-TPR) was performed on a FINESORB 3010C 243 adsorption system. The $\mathrm{NH}_{3}$ temperature programmed desorption ( $\left.\mathrm{NH}_{3}-\mathrm{TPD}\right)$ experiments were performed on a TP5079 TPDRO instrument equipped with a TCD detector.

\subsection{Catalytic activity tests and product analysis}

Hydrogenation reactions were performed in an agitated $2 \mathrm{~L}$ stainless steel batch reactor (Dalian Tongchan Autoclave Vessel Manufacturing Co., Ltd., China), whose design temperature was $623 \mathrm{~K}$ and design pressure $20 \mathrm{MPa} .470 \mathrm{~g}$ pine gum and $300 \mathrm{~g}$ turpentine oil were mixed together and heated in a water bath, followed by filtration. The reactor was charged with this filtrate, a specific amount of catalyst and then sealed, and the reaction temperature was $453 \mathrm{~K}$. The air was pumped out of the reactor to an absolute pressure of about $0.003 \mathrm{MPa}$, followed by charging with $\mathrm{N}_{2}$ to a pressure at $0.5 \mathrm{MPa}$ and holding for 10 min. Then, the $\mathrm{N}_{2}$ was pumped out, and the system was refilled with $\mathrm{N}_{2}$ to a pressure of $0.1 \mathrm{MPa}$. This replacement procedure was repeated twice. Subsequently, the reactor was filled with $\mathrm{H}_{2}$ to a pressure of $0.5 \mathrm{MPa}$ and was heated to the desired reaction temperature with continuous stirring at $100 \mathrm{rpm}$. When the required reaction temperature was attained, the stirring rate was increased to $500 \mathrm{rpm}$ and the $\mathrm{CO}_{2}$ pressure was filled to 4.0 MPa. On reaction completion, i.e. $1 \mathrm{~h}$, the reactor was cooled to room temperature.

The reaction species in the samples were methylated with $25 \%$ aqueous tetramethylammonium hydroxide (TMAH) solution (ASTM Standard D 5974-00) and quantitatively analyzed by gas chromatography (GC) (GC-7820, Agilent), while qualitative analyses were performed using GC-MS (QP5050A, Shimadzu). The gas chromatograph equipped with a fused silica capillary column was coated with DB-5 $(30 \mathrm{~m} \times 0.25 \mathrm{~mm}$ i.d. $\times 0.25 \mathrm{~m}$ film thickness, J\&W Scientific, USA) and a flame ionization detector (FID) using a temperature programmed GC as follows:

$$
\begin{gathered}
150{ }^{\circ} \mathrm{C} \stackrel{5^{\circ} \mathrm{C} \mathrm{min}}{\longrightarrow} 215{ }^{\circ} \mathrm{C} \stackrel{0.5^{\circ} \mathrm{Cmin}^{-1}}{\longrightarrow} 232{ }^{\circ} \mathrm{C} \stackrel{2^{\circ} \mathrm{C} \mathrm{min}^{-1}}{\longrightarrow} 250{ }^{\circ} \mathrm{C} \\
150{ }^{\circ} \mathrm{C} \stackrel{10^{\circ} \mathrm{C} \mathrm{min}^{-1}}{\longrightarrow} 215^{\circ} \mathrm{C} \stackrel{{ }^{\circ} \mathrm{C} \mathrm{min}^{-1}}{\longrightarrow} 232{ }^{\circ} \mathrm{C} \stackrel{3{ }^{\circ} \mathrm{C} \mathrm{min}^{-1}}{\longrightarrow} 250{ }^{\circ} \mathrm{C}
\end{gathered}
$$

The temperature of the gas chamber was $250{ }^{\circ} \mathrm{C}$ and $\mathrm{N}_{2}$ was used as the carrier gas with a flow rate of $25 \mathrm{~mL} \mathrm{~min}^{-1}$. 


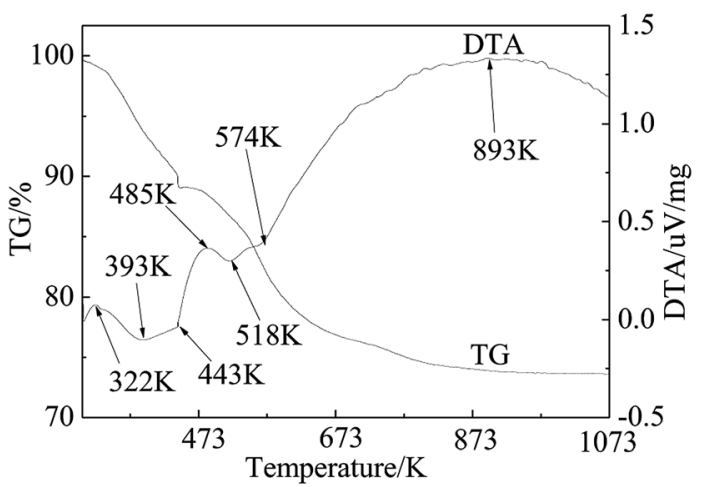

a

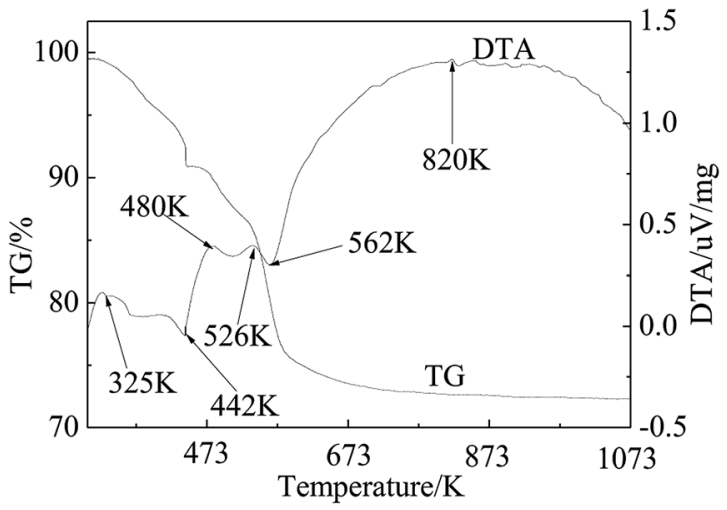

b

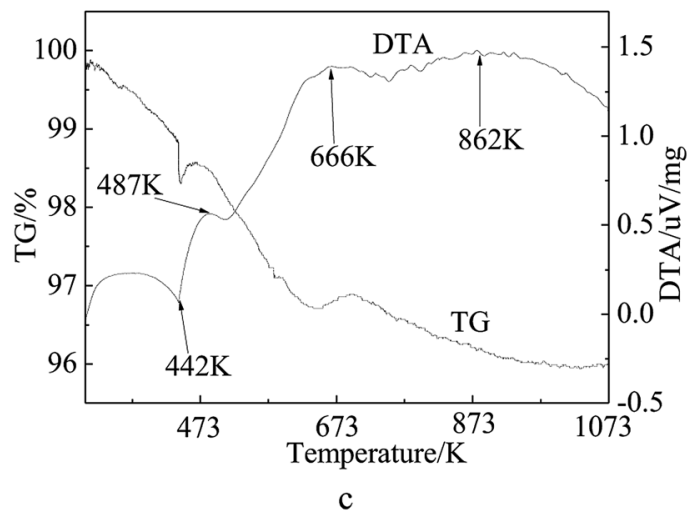

Fig. 6 TG-DTA curves of supported Ni catalysts and deactivated catalyst. (a) 15 wt\% Ni loaded fresh FCC catalyst by one step (b) 15 wt\% Ni loaded spent FCC catalyst (c) inactive catalyst.

\section{Results and discussion}

\subsection{Catalyst characterization}

Surface particle structure and morphology characterization was performed using SEM and the scans are depicted in Fig. 1. It can be seen from Fig. 1(a) that the spent FCC catalyst had serious agglomeration and the blocked pores present were due to the accumulation of carbon and the deposition of heavy metal, which caused the inactivation of the catalyst. Fig. 1(b) shows that the calcined spent FCC catalyst had less agglomeration with cleaner and bigger pore structures to some extent. This can also be found by the BET data in Table 1 that the surface area of the spent FCC catalyst is smaller than that of the calcined version, though with a minimal increase attributed to structure collapse. ${ }^{41,42}$ Many rhombus particles i.e. NiO grains, on the surface or between the layers of the supported NiO catalyst can be seen (Fig. 1(c)). As shown in Fig. 1(d), the grain size decreases after hydrogen reduction with the $\mathrm{Ni}$ grains possessing a smaller size than $\mathrm{NiO}^{43}$

Supposing that the Ni grain entered into the pore on the catalyst surface, the surface area, the pore volume and pore size of the supported $\mathrm{Ni}$ catalyst decreased compared with the nascent calcined spent FCC catalyst (Table 1). However, it has no effect on the reaction rate because the rate determining step is considered to be the reaction between atomic hydrogen and the adsorbed components in pine gum on $\mathrm{Ni}$ active sites. ${ }^{21}$ Fig. 1(e) further reveals that the catalyst recycled from the hydrogenation of pine gum still had Ni particles visible on the surface and hence possessed enough catalytic activity.

The microstructure of the catalyst sample was examined using XRD and the pattern in Fig. 2 suggests that the newly synthesized FCC catalyst exhibited Y type molecular sieve structure. ${ }^{\mathbf{4 4}}$ The XRD peaks of the spent FCC catalyst were widened and weakened compared with the fresh catalyst because of the collapsing molecular sieve structure during the reaction procedure. This is consistent with the SEM results discussed above. It can be seen that the sample (d) exhibited three peaks at $2 \theta$ of $37.16^{\circ}, 43.26^{\circ}$ and $62.88^{\circ}$, which could be ascribed respectively to the (101), (012) and (110) reflections of $\mathrm{NiO}$ with a face-centered cubic structure. ${ }^{45}$ The supported $\mathrm{Ni}$ catalyst exhibited two obvious, sharp diffraction peaks $(2 \theta=$ $44.559^{\circ}$ and $51.879^{\circ}$ ) corresponding to the (111) and (200) planes of the face-centered cubic structure of $\mathrm{Ni}$, confirming its successful incorporation onto the support after hydrogen reduction. Further, it was deduced that the metallic Ni was reduced sufficiently, with no further oxidation after storing in open air before the characterization. The catalytic activity of the already used catalyst (in the hydrogenation reaction) can be explained by comparing their XRD patterns with other supported Ni-based catalysts where both exhibited identical XRD peaks suggesting the presence of active Ni species.

FT-IR spectra of the catalytic samples are shown in Fig. 3. A strong band at $3470 \mathrm{~cm}^{-1}$ is related to the $\mathrm{H}-\mathrm{O}-\mathrm{H}$ stretching vibration, while the band at $1646 \mathrm{~cm}^{-1}$ is assigned to the 

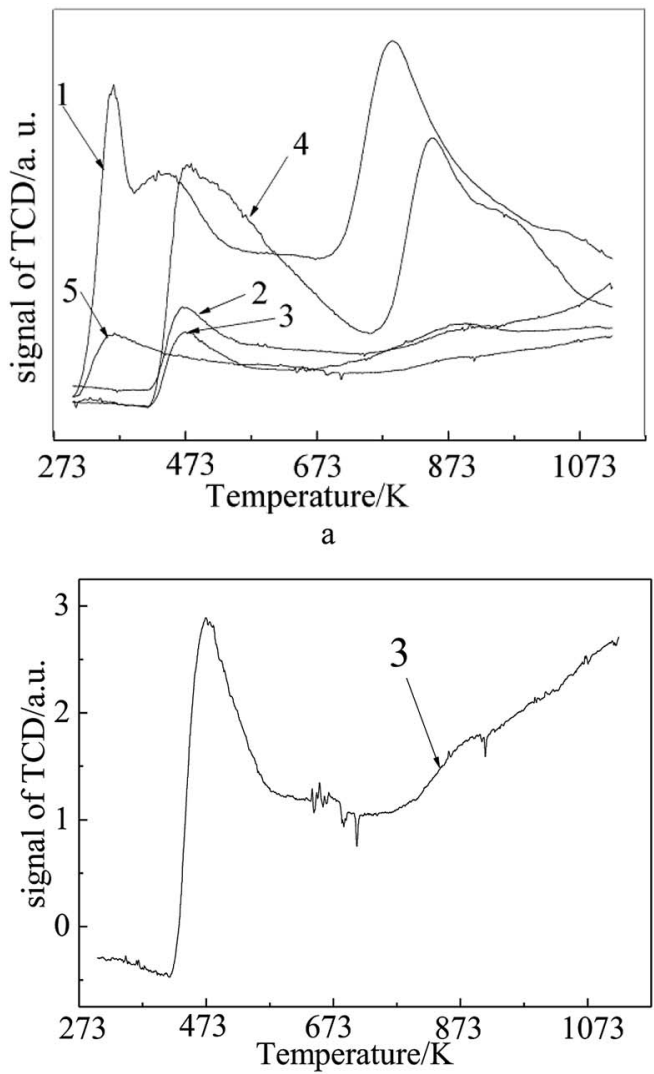

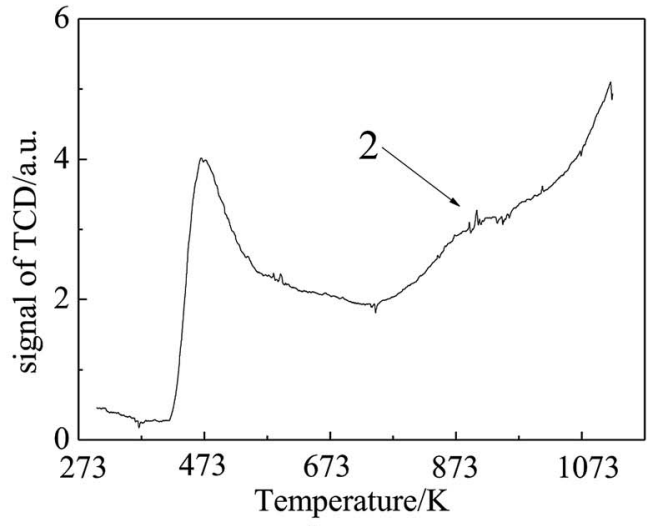

b

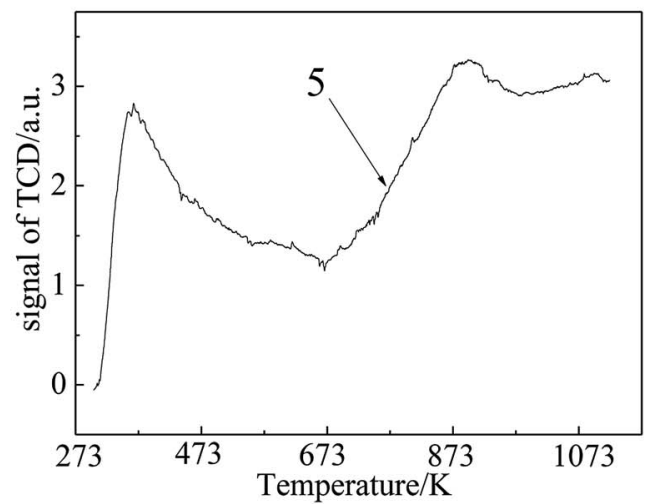

d

Fig. $7 \mathrm{NH}_{3}$-TPD profiles of (1) fresh FCC catalyst, (2) spent FCC catalyst, (3) calcined spent FCC catalyst, (4) NiO/fresh FCC catalyst, (5) NiO/spent FCC catalyst.

$\mathrm{H}-\mathrm{O}-\mathrm{H}$ bending vibration. ${ }^{46}$ Samples 3-5 all exhibited two wide absorption bands nearby $3470 \mathrm{~cm}^{-1}$ and $1646 \mathrm{~cm}^{-1}$, which were assigned to the association of $\mathrm{H}-\mathrm{O}-\mathrm{H}$. The absorptions near $1078 \mathrm{~cm}^{-1}$ and $455 \mathrm{~cm}^{-1}$ were assigned to the asymmetric stretching vibration and bending vibration of $\mathrm{Si}-\mathrm{O}$, respectively. ${ }^{47}$ The absorption band for the $\mathrm{Si}-\mathrm{H}$ (stretching) mode was observed around $2350 \mathrm{~cm}^{-1}$. The $\mathrm{Ni}$ catalyst derived from precursor (nickel nitrate) had no absorption at $985 \mathrm{~cm}^{-1}$ for Si$\mathrm{O}(\mathrm{H})-\mathrm{Ni},{ }^{48}$ suggesting the absence of a covalent bond between the metal and support. Sample 5 had an absorption feature near $3000-2800 \mathrm{~cm}^{-1}$ assigned to the stretching vibration of $\mathrm{C}-\mathrm{H}$, which demonstrates the association of used catalyst with the product molecules.

The $\mathrm{H}_{2}$-TPR profiles of the fresh and spent catalysts are depicted in Fig. 4(a), while Fig. 4(b) shows the fitting profile of the spent FCC catalyst. From the profiles, it can be observed that the spent FCC catalyst expressed one high temperature strong reduction peak at $1123{ }^{\circ} \mathrm{C}$ and one weak reduction peak at $670^{\circ} \mathrm{C}$, which indicates the presence of some metal oxide on the spent FCC catalyst that can be reduced. These two peaks can be assigned to the reduction of $\mathrm{NiAl}_{2} \mathrm{O}_{4}$ (or V oxide) and $\mathrm{NiO}$, which is confirmed by the XRD results mentioned above. The comparison of the curve 3,1 and 2 shows the main peaks of the latter moved to lower reduction temperatures, which is attributed to the adsorption of metal ion (or poison) over the catalyst surface in the FCC process (Fig. 5). Another factor that could lead to the decrease in reduction temperature of $\mathrm{NiO}$ is the presence of $\mathrm{La}_{2} \mathrm{O}_{3}{ }^{49}$ In addition, shoulder peaks were detected around $780 \mathrm{~K}$ on curve 1 and curve 2, while curve 3 has two shoulder peaks at $673 \mathrm{~K}$ and $780 \mathrm{~K}$, respectively. The peak at 780 $\mathrm{K}$ is attributed to the reduction of $\mathrm{NiO}$ in close contact with the support. All these data show that the fresh FCC catalyst had a strong interaction with $\mathrm{NiO}$, which improved the dispersion of $\mathrm{Ni}$ and hindered the catalyst sintering and agglomeration. It can be seen from Fig. 4 that the optimum reduction temperature was about $673 \mathrm{~K}$, which is in good agreement with the results reported in Fig. 8(b).

The TG curve presented in Fig. 6 shows a three-step weight loss pattern for the precursors of the catalyst (Fig. 6(a) and (b)) and inactivated catalyst (Fig. 6(c)). The first step below $440 \mathrm{~K}$ is assigned to the weight loss of the physisorbed and interlayer water. ${ }^{50,51}$ It can be seen from the first two figures that the second and the third steps occurred at $440 \mathrm{~K}$ and $550 \mathrm{~K}$, respectively, showing a total weight loss of $16 \%$, which is consistent with the theoretical value of $18.8 \%$ caused by the decomposition of $\mathrm{Ni}\left(\mathrm{NO}_{3}\right)_{2}$. The positions of these steps coincided well with those of the endothermic peaks observed in the DTA patterns. As shown in Fig. 6(a), the weight loss curve does not level out until $900 \mathrm{~K}$ as compared with Fig. 6(b) which levels out at $673 \mathrm{~K}$. The inflexions around $567 \mathrm{~K}$ on the TG curves of the samples correspond to the decomposition of groups and rupture of molecular bonds. Apparently, the third step on the 

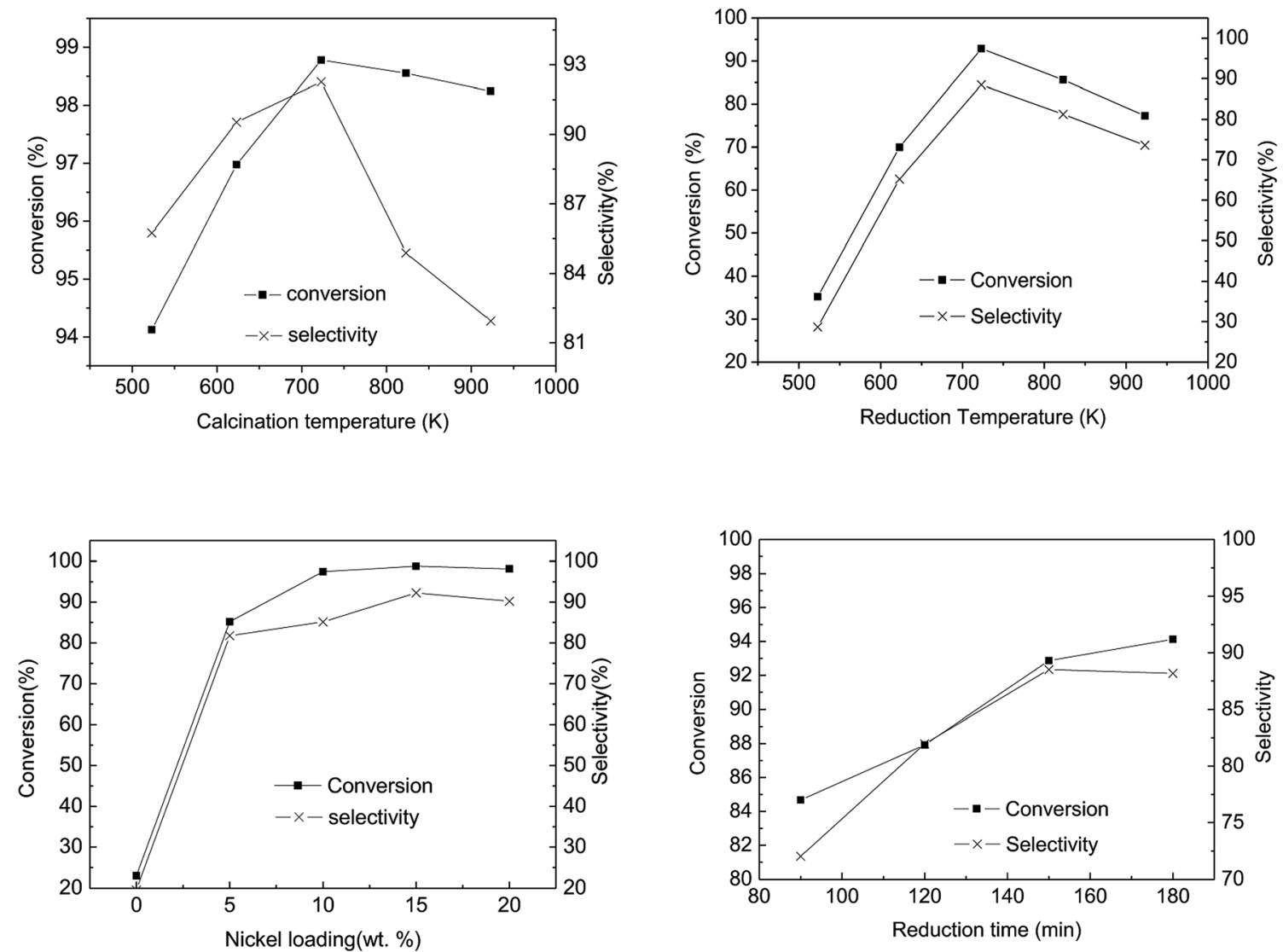

Fig. 8 Conversion and selectivity of rosin acid with calcination temperature, reduction temperature, Ni-loading and reduction time of catalyst (temperature $453 \mathrm{~K}$, pressure $4.0 \mathrm{MPa}$, stirring rate $500 \mathrm{rpm}$, reaction time $1 \mathrm{~h}$, catalyst dose $5 \mathrm{wt} \%$, reactant $770 \mathrm{~g}$, and the maximum relative error was $2.5 \%$.).

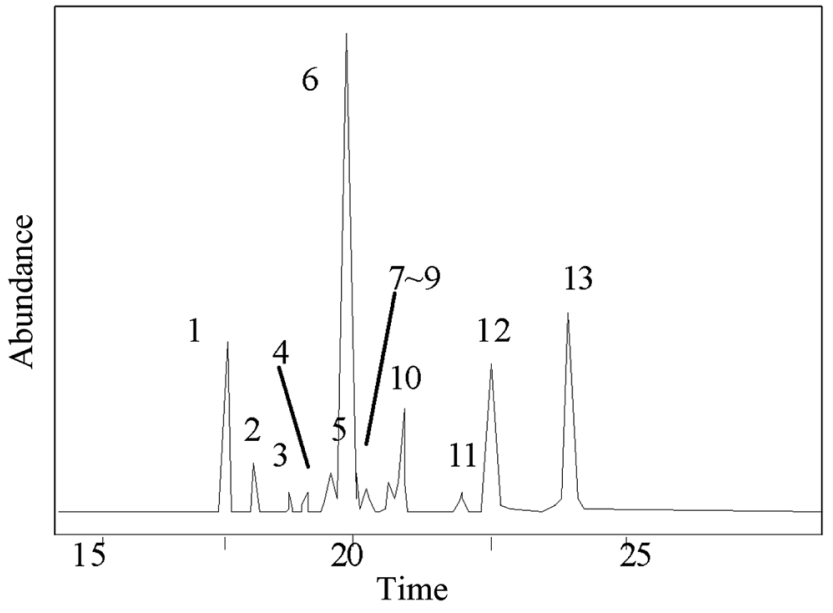

Fig. 9 GC-MS chromatogram of methylated acid fraction in rosin.

$\mathrm{Ni} /$ fresh FCC catalyst curve is longer than on the Ni/spent FCC catalyst, resulting from different interactions between $\mathrm{Ni}$ and the support molecules. It can also be observed from $\mathrm{H}_{2}$-TPR (Fig. 4) that there was a stronger interaction between $\mathrm{Ni}$ ions and the fresh FCC catalyst support compared with spent FCC catalyst. Fig. 6(d) shows a weak weight-gain peak at $666 \mathrm{~K}$, corresponding to the DTA pattern, because Ni ions on the inactivated catalyst had already been oxidized in the air. On average, the TG pattern exhibited a $4 \%$ weight loss because of the coke deposition in the catalytic reaction.

The $\mathrm{NH}_{3}$-TPD measurement was performed to evaluate the strength and number of acidic sites on the samples. In Fig. 7, peaks below $573 \mathrm{~K}$ represent weak acidic sites, those between $573 \mathrm{~K}$ to $723 \mathrm{~K}$ correspond to medium strength, while those above $550 \mathrm{~K}$ correspond to strong acidic sites. From Fig. 7, it is clear that the fresh FCC catalyst shows broad desorption in the range of 273-1073 K, and there exist three kinds of acidic sites on the fresh FCC catalyst (weak acid sites at $363 \mathrm{~K}$ and $446 \mathrm{~K}$ and strong acid sites around $787 \mathrm{~K}$ ). In case of the Ni-loaded fresh FCC catalyst, all the desorption peaks move to higher temperatures, suggesting stronger acidic sites are caused by the interaction between $\mathrm{Ni}$ ions and the support. These strong acidic sites in the case of spent FCC catalyst obviously disappeared, and the curve exhibits a decrease in the weak acid amount with the desorption peak moved to higher temperatures, which is concomitantly ascribed to a collapsed catalyst structure and metal deposition via FCC process. After calcination, the spent FCC catalyst showed a slight decrease in weak acid amount and almost did not change in acid site strength. Otherwise, it detected a weak desorption peak ranging from 633 $\mathrm{K}$ to $673 \mathrm{~K}$ on the calcined spent FCC catalyst, implying a few weak acid sites were recovered after removal of the coke 
Table 2 Main components distribution of the acid fraction in pine gum

\begin{tabular}{|c|c|c|c|c|c|c|c|}
\hline No. & $\begin{array}{l}\text { Retention time } \\
(\mathrm{min})\end{array}$ & Compound & $\begin{array}{l}\text { Molecular } \\
\text { formula }\end{array}$ & $\begin{array}{l}\text { Molecular weight } \\
\left(\mathrm{g} \mathrm{mol}^{-1}\right)\end{array}$ & $\begin{array}{l}\text { Similarity } \\
\text { degree }(\%)\end{array}$ & $\begin{array}{l}\text { Relative } \\
\text { content wt } \%\end{array}$ & $\begin{array}{l}\text { No. in } \\
\text { Fig. } 11\end{array}$ \\
\hline 1 & 17.694 & Pimaric acid & $\mathrm{C}_{20} \mathrm{H}_{30} \mathrm{O}_{2}$ & 302 & 89 & 7.78 & $\mathrm{n}$ \\
\hline 3 & 18.601 & 8(14)-Pimarenoic acid & $\mathrm{C}_{20} \mathrm{H}_{30} \mathrm{O}_{2}$ & 302 & 96 & 0.53 & $\mathrm{~b}$ \\
\hline 4 & 18.903 & $\begin{array}{l}\text { Pimaric acid decarboxylation } \\
\text { products }\end{array}$ & $\mathrm{C}_{20} \mathrm{H}_{32}$ & 272 & 96 & 0.72 & - \\
\hline 7 & 20.029 & 13-Abietenoic acid & $\mathrm{C}_{20} \mathrm{H}_{32} \mathrm{O}_{2}$ & 304 & 90 & 3.62 & $\mathrm{e}$ \\
\hline 8 & 20.232 & 13ß-7-Abietenoic acid & $\mathrm{C}_{20} \mathrm{H}_{32} \mathrm{O}_{2}$ & 304 & 98 & 1.67 & $\mathrm{f}$ \\
\hline 9 & 20.488 & $8 \alpha-13 \beta$-Abietanoic acid & $\mathrm{C}_{20} \mathrm{H}_{32} \mathrm{O}_{2}$ & 304 & 95 & 0.60 & $\mathrm{~h}$ \\
\hline 10 & 20.607 & Dehydroabietic acid & $\mathrm{C}_{20} \mathrm{H}_{28} \mathrm{O}_{2}$ & 300 & 96 & 3.02 & $\mathrm{i}$ \\
\hline 11 & 21.988 & Juniper acid & $\mathrm{C}_{20} \mathrm{H}_{30} \mathrm{O}_{2}$ & 304 & 96 & 0.31 & - \\
\hline 12 & 22.114 & Abietic acid & $\mathrm{C}_{20} \mathrm{H}_{30} \mathrm{O}_{2}$ & 302 & 95 & 10.85 & $\mathrm{k}$ \\
\hline
\end{tabular}

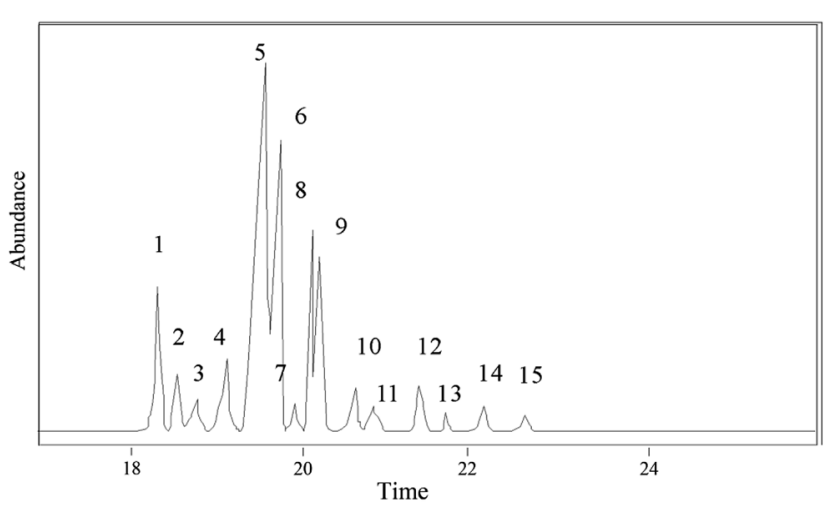

Fig. 10 GC-MS chromatogram of methylated acid fraction in hydrogenated rosin.

deposits with calcination. When the spent FCC catalyst was loaded with NiO, the strong acid site was detected concurrently with the weak desorption peak moving to lower temperatures.

\subsection{Catalytic activity evaluation}

The pine gum hydrogenation reaction was used to evaluate the catalytic activity at a temperature of $453 \mathrm{~K}, 4 \mathrm{MPa}$ pressure, $500 \mathrm{rpm}$ stirring speed, $1 \mathrm{~h}$ reaction time, using a catalyst dose of $5 \%$. As there was a mixture of reactants, the conversion and selectivity are obtained by the follow equations

$$
\begin{gathered}
\text { Conversion }(\%)=\frac{W_{\mathrm{R}}-W_{\mathrm{P}}}{W_{\mathrm{R}}} \times 100 \\
\text { Selectivity }(\%)=\frac{W_{\mathrm{R}}-W_{\mathrm{RD}}-W_{\mathrm{P}}+W_{\mathrm{PD}}}{W_{\mathrm{R}}} \times 100
\end{gathered}
$$

$W_{\mathrm{R}}$ and $W_{\mathrm{P}}$ are the mass percent of the sum of the palustric acid, abietic acid, and neoabietic acid in reactants and product, respectively. $W_{\mathrm{RD}}$ and $W_{\mathrm{PD}}$ are the mass percent of the dehydroabietic acid in the reactant and product, respectively.

Fig. 8(a) illustrates the influence of calcination temperature on the conversion and selectivity of the abietic acid over the asprepared catalysts. It can be seen that the maximum conversion

\begin{tabular}{|c|c|c|c|c|c|c|c|}
\hline 1 & 18.42 & 8-Pimarenoic acid & $\mathrm{C}_{20} \mathrm{H}_{32} \mathrm{O}_{2}$ & 304 & 90 & 2.96 & a \\
\hline 3 & 18.88 & $13 \beta-8(14)$-Abietenoic acid & $\mathrm{C}_{20} \mathrm{H}_{32} \mathrm{O}_{2}$ & 304 & 92 & 0.93 & $\mathrm{c}$ \\
\hline 4 & 19.27 & 8(14)-Isopimarenoic acid & $\mathrm{C}_{20} \mathrm{H}_{32} \mathrm{O}_{2}$ & 304 & 96 & 5.84 & $\mathrm{~d}$ \\
\hline 5 & 19.66 & 13-Abietenoic acid & $\mathrm{C}_{20} \mathrm{H}_{32} \mathrm{O}_{2}$ & 304 & 90 & 41.12 & $\mathrm{e}$ \\
\hline 8 & 20.16 & $8 \alpha-13 \beta$-Abietanoic acid & $\mathrm{C}_{20} \mathrm{H}_{34} \mathrm{O}_{2}$ & 306 & 95 & 13.89 & $\mathrm{~h}$ \\
\hline 9 & 20.21 & Dehydroabietic acid & $\mathrm{C}_{20} \mathrm{H}_{28} \mathrm{O}_{2}$ & 300 & 96 & 8.06 & $\mathrm{i}$ \\
\hline 10 & 20.67 & $13 \beta$-8-Abietenoic acid & $\mathrm{C}_{20} \mathrm{H}_{32} \mathrm{O}_{2}$ & 304 & 90 & 0.49 & j \\
\hline 11 & 20.77 & Juniper acid & $\mathrm{C}_{20} \mathrm{H}_{30} \mathrm{O}_{2}$ & 304 & 96 & 0.30 & - \\
\hline 12 & 21.46 & Abietic acid & $\mathrm{C}_{20} \mathrm{H}_{30} \mathrm{O}_{2}$ & 302 & 95 & 1.20 & $\mathrm{k}$ \\
\hline 13 & 21.73 & Unknown & - & - & - & 0.63 & - \\
\hline
\end{tabular}

Table 3 Main products distribution of the acid fraction in hydrogenated rosin product 


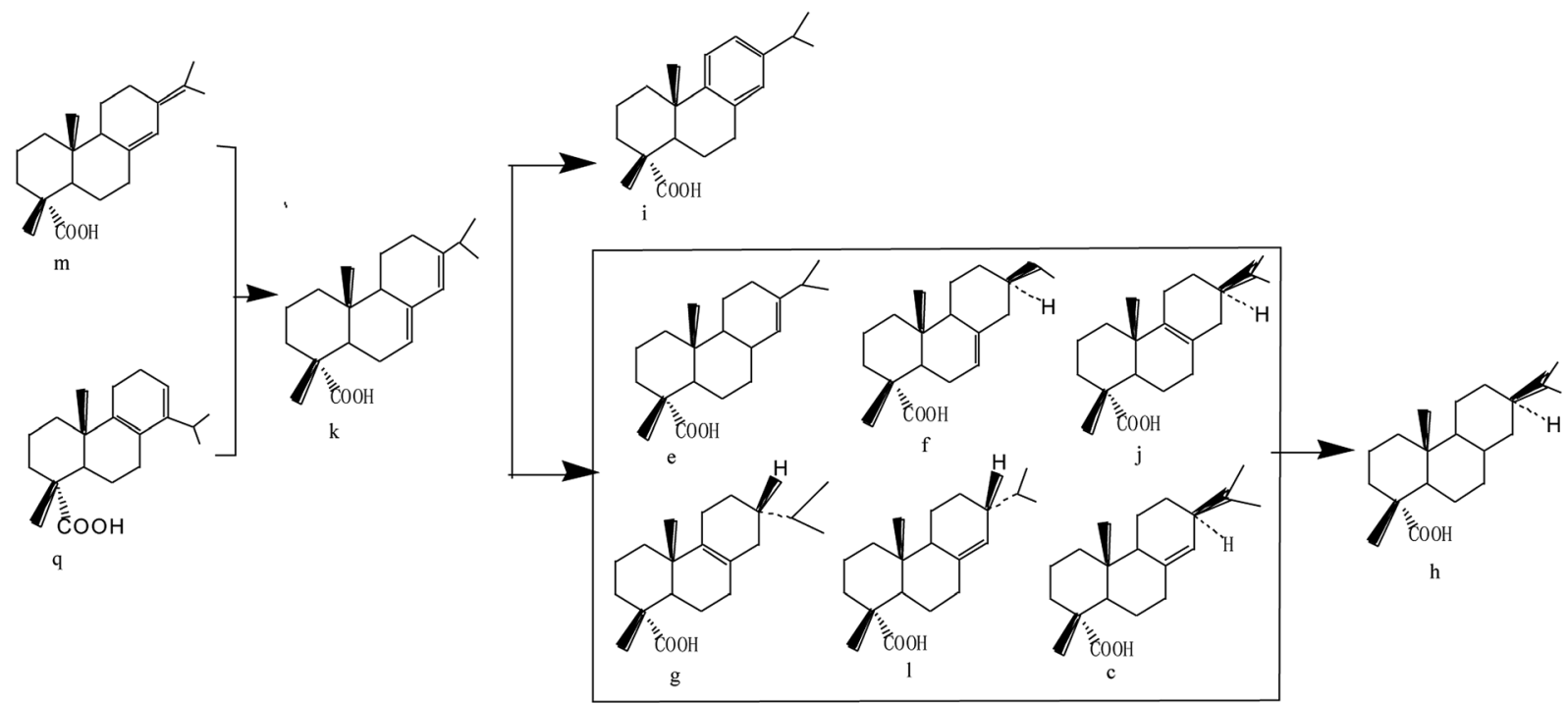

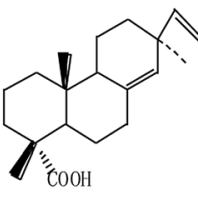

$\mathrm{n}$

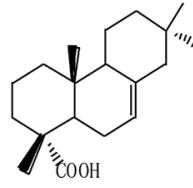

$\mathrm{p}$

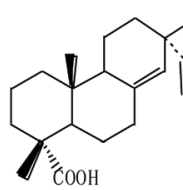

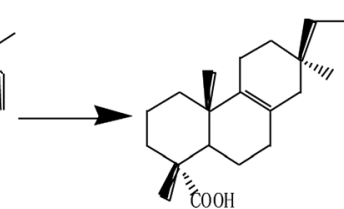

a

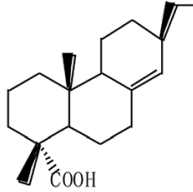

b

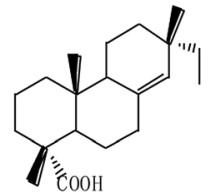

d

Fig. 11 The mechanism of pine gum hydrogenation reaction.

and selectivity occurred at $723 \mathrm{~K}$, while a further rise in temperature led to a decrease in both of these properties. The hydrogenation activity of the catalysts decreased at a calcination temperature below $573 \mathrm{~K}$, which may be attributed to the fact that $\mathrm{Ni}(\mathrm{NO})_{3}$ cannot be decomposed completely at such a low temperature, while the reverse happened above $723 \mathrm{~K}$ (Fig. 8). At $723 \mathrm{~K}$, the conversion and selectivity achieved $98.8 \%$ and $92.3 \%$, higher than that reported by Wang ${ }^{18}$ with a $95 \%$ conversion and $80 \%$ selectivity, respectively. The hydrogenation activity gradually decreased with increasing catalyst calcination temperature, which may be due to the formation of agglomerates of $\mathrm{NiO}$ grains..$^{52}$

The catalytic activity as a function of reduction temperature, as shown in Fig. 8(b), shows a marked relation between the two parameters. In Fig. 8(b), as the reduction temperature elevated from $523 \mathrm{~K}$ to $923 \mathrm{~K}$, the conversion and the selectivity of the abietic type acid increased from $30 \%$ to $90 \%$. It is worth noting that the supported Ni catalyst (prepared via an impregnation method) resulted in a nickel-aluminum spinel structure, which required a higher reduction temperature compared to other methods ${ }^{53}$ It is worth mentioning that a further increase in reduction temperature can lead to a gradual increase in $\mathrm{Ni}$ particle size, resulting in the lowering of specific surface area with an ultimately lower Ni particle dispersion.

Fig. 8(c) illustrates the influence of Ni loading on catalytic activity. The untreated spent FCC catalyst (without Ni loading) in pine gum hydrogenation exhibited $20 \%$ conversion of abietic type acid and selectivity of the desired products, which increased to $85 \%$ after $5 \% \mathrm{Ni}$ loading. The conversion and selectivity remained in a range of $80-100 \%$ with further loadings, while the maximum was attained at $15 \%$ Ni loadings.

As the reduction proceeded, $\mathrm{Ni}$ active sites were generated and the catalyst's abietic acid hydrogenation activity increased (Fig. 8(d)). Apparently, the range of conversion and the selectivity narrowed with increasing reduction time, whereas at a reduction time $>150 \mathrm{~min}$, the selectivity declined slowly. This may be attributed to the fact that the particle size grew larger with increasing reduction time, leading to agglomerate formation.

\subsection{Reaction mechanism}

The GC-MS results of pine gum are shown in Fig. 9 and Table 2, which shows that there were 13 components in the reaction mixture among which 12 were identified.

The hydrogenation products of pine gum after $1 \mathrm{~h}$ reaction were analyzed and identified by GC-MS. In total 14 components were identified, which are shown in Fig. 10 and Table 3.

According to the GC-MS results and in light of some previous reports, ${ }^{54,55}$ the proposed reaction mechanism is shown in Fig. 11. Palustric acid and neoabietic acid are converted into abietic acid because of thermal isomerization. Then, 6 isomers of the dihydroabietic acid and tetrahydroabietic acid are obtained by hydrogenation reaction of abietic acid. Comparing dehydroabietic acid in Table 2 with Table 3, it was found that the quantity of dehydroabietic acid increased from $3.02 \mathrm{wt} \%$ to $8.06 \mathrm{wt} \%$, which demonstrated that the hydrogenation reaction was accompanied by a dehydrogenation reaction. Pimaric acid, 
isopimaric acid and sandaracopimaric acid are hydrogenated on the side chain, while cyclic olefinic bond isomerism occurred instead of hydrogenation attributed to steric hindrance.

\section{Conclusions}

In this study, the pine gum hydrogenation reaction was used to evaluate the catalytic activity of a Ni-loaded spent FCC catalyst at a temperature of $453 \mathrm{~K}, 4 \mathrm{MPa}$ pressure, stirring rate of $500 \mathrm{rpm}, 1 \mathrm{~h}$ reaction time, and catalyst dose of $5 \%$ as optimum conditions for maximum conversion. A Ni loading of 15\%, reduced at $723 \mathrm{~K}$ for $2.5 \mathrm{~h}$, exhibited the maximum catalytic activity. BET and SEM results show that the spent FCC catalyst possessed a layered structure, while the porosity and surface area were improved by calcination. XRD and IR analysis indicated the absence of any covalent bonds between the metal and support. $\mathrm{H}_{2}$-TPR and TG results indicated that the fresh FCC catalyst had strong interaction with $\mathrm{NiO}$, which improved the dispersion of $\mathrm{Ni}$ and hindered catalyst sintering. $\mathrm{H}_{2}$-TPD profiles indicated that the strength of acid sites increased because of interaction between the Ni ions and support. GC-MS results of pine gum and hydrogenation products indicated there were 13 components in the reaction mixture, while 14 components were identified in the hydrogenation products. Based on GC-MS results, a proper reaction mechanism was proposed. The present study, based on the utilization of spent FCC catalyst, is assumed to be highly cost-effective and environment-friendly and can be applied on an industrial level for the hydrogenation of pine gum, leading to the production of useful chemicals.

\section{Conflicts of interest}

There are no conflicts of interest to declare.

\section{Acknowledgements}

The authors gratefully acknowledge the financial support for this research from the National Natural Science Foundation of China (Grant No. 21566002, 21878056 and 31560241) and the Key Laboratory of Petrochemical Resource Processing and Process Intensification Technology (Grant No. 2016Z002).

\section{References}

1 D. Xi, L. Hua, P. Liu, Z. Hua, Q. Wen, C. Gu and H. Yuan, Comparative analysis of resin resource in rosin producing areas in china, J. Southwest For. Univ., 2010, 30(1), 73-79.

2 D. F. Zinkel and J. Russell, Naval stores: production, chemistry, utilization, Pulp Chemicals Association, New York, 1989.

3 I. M. Klein, US Pat. 3,232,895, 1961-05-26.

4 S. Tsuchida, Y. Kodama and H. Hara, US Pat. 4,618,640, 1983-07-27.

5 Y. K. S. Tsuchida and H. Hara, US Pat. 3,222,419, 1962-07-05. 6 I. J. Balinth, US Pat. 4,147,831, 1977-08-31.

7 H. S. Do, J. H. Park and H. J. Kim, Synthesis and characteristics of photoactive-hydrogenated rosin epoxy methacrylate for pressure sensitive adhesives, J. Appl. Polym. Sci., 2009, 111(3), 1172-1176.

8 A. Matsumura, S. Shigematsu and T. Itou, US Pat. 4,981,939, 1986-11-17.

9 P. Guo, M. Danish, P. Du, Z. Kong and R. Guan, Viscoelastic and adhesive properties of polystyrene-hydrogenated (3,4polyisoprene and 1,4-polyisoprene)-polystyrene and polymethyl methacrylate-polybutyl acrylate-polymethyl methacrylate-based HMPSA, J. Adhes. Sci. Technol., 2014, 28(5), 417-433.

10 M. Takemoto, M. Kajiyama, H. Mizumachi, A. Takemura and H. Ono, Miscibility and adhesive properties of ethylene vinyl acetate copolymer (EVA)-based hot-melt adhesives. I. Adhesive tensile strength, J. Appl. Polym. Sci., 2002, 83(4), 719-725.

11 M. Gillard, F. M. Cattiaux, M. Vos and J. Prinsen, EP Pat. 2,399,963, 2010-04-20.

12 A. Matsumura, T. Itou, T. Kusuda and S. Shigematsu, US Pat. 4,968,575, 1987-07-23.

13 E. A. Brled, US Pat. 2,510,063, 1948-07-20.

14 E. R. Koch, L. P. Abbazia and W. J. Puglia, US Pat. 4,187,320, 1978-05-01.

15 S. DeTora and R. P. D'amelia, US Pat. 4,459,311, 1983-01-03. 16 H. Wang, T. T. H. Nguyen, S. Li, T. Liang, Y. Zhang and J. Li, Quantitative structure-activity relationship of antifungal activity of rosin derivatives, Bioorg. Med. Chem. Lett., 2015, 25(2), 347-354.

17 A. L. Glasebrook, US Pat. 2,776,276, 1953-08-18.

18 L. Wang, X. Chen, W. Sun, J. Liang, X. Xu and Z. Tong, Kinetic model for the catalytic disproportionation of pine oleoresin over Pd/C catalyst, Ind. Crops Prod., 2013, 49, 1-9.

19 L. Wang, X. Chen, J. Liang, Y. Chen, X. Pu and Z. Tong, Kinetics of the catalytic isomerization and disproportionation of rosin over carbon-supported palladium, Chem. Eng. J., 2009, 152(1), 242-250.

20 Z. Cheng, Natural resin process technology, China Forestry Publishing House, Beijing, 1996.

21 M. Wang, S. Liu, L. Li, S. Yu, C. Xie and Z. Song, Hydrogenation of rosin over PVP-stabilized Pd nanoparticles in aqueous/organic biphasic system, Res. Chem. Intermed., 2016, 42(6), 6181-6190.

22 Y. Huang, L. Wang, X. Chen, Q. Xie, P. Gan, X. Wei and J. Liang, LDH-derived Ni catalyst as an effective catalyst in colophony hydrogenation and process optimization using response surface methodology, J. Taiwan Inst. Chem. Eng., 2016, 60, 229-235.

23 C. Wei, X. Chen, J. Xue, X. Wei, J. Liang, R. Liang and L. Wang, A small eggshell Ni/SFC3R catalyst for $\mathrm{C}_{5}$ petroleum resin hydrogenation: preparation and characterization, RSC Adv., 2016, 6(54), 49113-49122.

24 J. W. Chen, Catalytic cracking technology and engineering, China Petrochemical Press, Beijing, 2005.

25 P. Magnoux, H. S. Cerqueira and M. Guisnet, Evolution of coke composition during ageing under nitrogen, Appl. Catal., A, 2002, 235(1), 93-99. 
26 S. Du, D. P. Gamliel, M. V. Giotto, J. A. Valla and G. M. Bollas, Coke formation of model compounds relevant to pyrolysis bio-oil over ZSM-5, Appl. Catal., A, 2016, 513, 67-81.

27 D. M. Bibby, R. F. Howe and G. D. Mclellan, Coke formation in high-silica zeolites, Appl. Catal., A, 1992, 93(1), 1-34.

28 B. Behera and S. S. Ray, Structural changes of FCC catalyst from fresh to regeneration stages and associated coke in a FCC refining unit: a multinuclear solid state NMR approach, Catal. Today, 2009, 141(1), 195-204.

29 O. Bayraktar, Bioleaching of nickel from equilibrium fluid catalytic cracking catalysts, World J. Microbiol. Biotechnol., 2005, 21(5), 661-665.

30 A. de Rezende Pinho, M. B. de Almeida, F. L. Mendes, L. C. Casavechia, M. S. Talmadge, C. M. Kinchin and H. L. Chum, Fast pyrolysis oil from pinewood chips coprocessing with vacuum gas oil in an FCC unit for second generation fuel production, Fuel, 2017, 188, 462-473.

31 L. Wang, H. Guo, X. Chen, Y. Huang, L. Ren and S. Ding, Kinetic study of the hydrogenation of a monoterpene over spent FCC catalyst-supported nickel, Can. J. Chem. Eng., 2015, 93(10), 1770-1779.

32 Y. Lu, M.-Y. He, X.-T. Shu and B.-N. Zong, Exploratory study on upgrading 1-butene using spent FCC catalyst/additive under simulated conditions of FCCU's stripper, Appl. Catal., A, 2003, 255(2), 345-347.

$33 \mathrm{Y}$. H. Lin and M. H. Yang, Catalytic conversion of commingled polymer waste into chemicals and fuels over spent FCC commercial catalyst in a fluidised-bed reactor, Appl. Catal., B, 2007, 69(3), 145-153.

34 Y. H. Lin and M. H. Yang, Catalytic pyrolysis of polyolefin waste into valuable hydrocarbons over reused catalyst from refinery FCC units, Appl. Catal., A, 2007, 328(2), 132-139.

35 Y. H. Lin and M. H. Yang, Chemical catalysed recycling of polypropylene over a spent FCC catalyst and various commercial cracking catalysts using TGA, Thermochim. Acta, 2008, 470(1), 52-59.

36 S. Ali, A. Garforth, D. Harris, D. Rawlence and Y. Uemichi, Polymer waste recycling over "used" catalysts, Catal. Today, 2002, 75(1), 247-255.

37 S. Zheng, S. Huang, D. Qian, K. Tang and J. Yi, Modification of FCC waste catalyst and its adsorption performance for heavy metal ions, Acta Pet. Sin., Pet. Process. Sect., 2010, 26(4), 612-616.

38 S. M. Shah and H. Tu, US Pat. 4,280,897, 1980-05-27.

39 Y. Muhammad and C. Li, Dibenzothiophene hydrodesulfurization using in situ generated hydrogen over Pd promoted alumina-based catalysts, Fuel Process. Technol., 2011, 92(3), 624-630.

40 Y. Muhammad, Y. Lu, C. Shen and C. Li, Dibenzothiophene hydrodesulfurization over $\mathrm{Ru}$ promoted alumina based catalysts using in situ generated hydrogen, Energy Convers. Manage., 2011, 52(2), 1364-1370.

41 T. H. Nguyen, P. T. Ngo, T. V. Tran, S. Nguyen, D. M. Vu, Q. L. Ha and T. T. Dang, Effect of hydrothermal conditions on the catalytic deactivation of a fluid cracking catalyst, Energy Convers. Manage., 2013, 109(2), 563-574.

42 S. J. Silva, R. M. de Jesus-Neto, R. A. Fiuza, J. P. Gonçalves, A. J. Mascarenhas and H. M. Andrade, Alkali-activation of spent fluid cracking catalysts for $\mathrm{CO}_{2}$ capture, Microporous Mesoporous Mater., 2016, 232, 1-12.

43 N. Deraz, M. Selim and M. Ramadan, Processing and properties of nanocrystalline $\mathrm{Ni}$ and NiO catalysts, Mater. Chem. Phys., 2009, 113(1), 269-275.

44 S. Chandrasekhar and P. Pramada, A precursor for cordierite ceramics, Appl. Clay Sci., 2004, 27(3), 187-198.

45 A. D. Khalaji and D. Das, Synthesis and characterizations of NiO nanoparticles via solid-state thermal decomposition of nickel (II) Schiff base complexes, Int. Nano Lett., 2014, 4(3), 117.

46 J. Hao, H. Wang, S. Shi, R. Lu, T. Wang, G. Li and H. Sun, Phase behaviour and microstructures of microemulsions (I), Sci. China, Ser. B: Chem., 1997, 40(3), 225-235.

47 X. Feng, X. Niu, B. A. I. Xue, X. M. Liu and H. H. Sun, Cementing properties of oil shale ash, J. China Univ. Min. Technol., 2007, 17(4), 498-502.

48 Y. Shu, Y. Shao, X. Wei, X. Wang, Q. Sun, Q. Zhang and L. Li, Synthesis and characterization of Ni-MCM-41 for methyl blue adsorption, Microporous Mesoporous Mater., 2015, 214, 88-94.

49 W. Nabgan, T. A. T. Abdullah, R. Mat, B. Nabgan, A. A. Jalil, L. Firmansyah and S. Triwahyono, Production of hydrogen via steam reforming of acetic acid over $\mathrm{Ni}$ and $\mathrm{Co}$ supported on $\mathrm{La}_{2} \mathrm{O}_{3}$ catalyst, Int. J. Hydrogen Energy, 2017, 42(14), 8975-8985.

50 I. Cota, E. Ramírez, F. Medina, J. E. Sueiras, G. Layrac and D. Tichit, Highly basic catalysts obtained by intercalation of La-containing anionic complexes in layered double hydroxides, Appl. Catal., A, 2010, 382(2), 272-276.

51 S. Casenave, H. Martinez, C. Guimon, A. Auroux and V. Hulea, Acid-base properties of $\mathrm{Mg}-\mathrm{Ni}-\mathrm{Al}$ mixed oxides using LDH as precursors, Thermochim. Acta, 2001, 379(1), 85-93.

52 X. Xin, Z. Lv, B. Zhou, X. Huang, R. Zhu, X. Sha and W. Su, Effect of synthesis conditions on the performance of weakly agglomerated nanocrystalline NiO, J. Alloys Compd., 2007, 427(1), 251-255.

53 Y. song, X. Dong and W. Lin, A study of Ni-Ce/ $/ \mathrm{Al}_{2} \mathrm{O}_{3}$ catalysts for catalytic reforming of $\mathrm{CH}_{4}, \mathrm{CO}_{2}$ and $\mathrm{O}_{2}$ to syngas, J. South China Univ. Technol., Nat. Sci., 2002, 30(8), 16-19.

54 M. Besson, P. Gallezot and C. pinel, Conversion of biomass into chemicals over metal catalysts, Chem. Rev., 2013, 114(3), 1827-1870.

55 Y. Y. Huang, L. L. Wang, X. P. Chen, X. J. Wei, J. Z. Liang and W. Li, Intrinsic kinetics study of rosin hydrogenation on a nickel catalyst supported on spent equilibrium catalyst, RSC Adv., 2017, 7(41), 25780-25788. 